\title{
New Integrated Breeding Evaluation Method Used for German Warm-blooded Horses
}

\author{
Hinni Luehrs-Behnke - Rainer Roehe - \\ Ernst Kalm
}

Institut für Tierzucht und Tierhaltung der Christian-AlbrechtsUniversität, D-24098 Kiel, Germany

\begin{abstract}
SUMMARY
In Germany, the new integrated breeding value estimation is based on a multiple-trait animal model, considering simultaneously information from performance test of stallion on station, performance test of mares as well as competition results of sport horses. The objective of this study was to estimated the genetic parameters of the traits used in the integrated breeding evaluation including all German warmblood breeds. The analysed data consisted of 4527, 40670 and six million records for performance tests of stallions, mares and for competition results, respectively. Genetic parameters were estimated with a multivariate BLUP animal model. Heritabilities for traits obtained from stallions tested on station ranged from 0.33 (jumping under rider) to 0.51 (trot) and for the traits from mare performance test from 0.27 (walk) to 0.38 (trot). Genetic correlations between corresponding traits recorded on performance test of stallions and mares ranged from 0.87 (canter) to 0.98 (free jumping). Heritabilities of competition traits from horses (build up for sport) were estimated as 0.12 and 0.11 for dressage and jumping, respectively. The use of all traits for estimation of genetic values of horses is expected to reduce pre-selection and optimal combines all information resources based on the estimated genetic parameters.
\end{abstract}

Keywords: Genetic parameters; Breeding value estimation; Selection; Horse

\section{INTRODUCTION}

In Germany, the main disadvantage of the past breeding value estimation for competition is the preselection of the horses regarding its suitability and talent for the sport discipline jumping or dressage. In addition only the best $25 \%$ of the started horses, the placed horses, could be considered by the trait natural logarithm earnings of placing. By this pre-selection the genetic variance will be underestimated and the breeding values of the horses are biased.

At present, data can be used, which were collected by TORIS (Turnier-, ORganisations- und InformationsSystem). TORIS is a competitionprogram from the German FN (Federation Equestre Nationale) in which the promoters are recording the results at competition (Hassenstein, 1998). Thus, all started horses can be considered in the analyses. The trait square root of place were developed and there is a gain of information through the consideration of all starters (Hassenstein, 1998). The stallion and mare performance test delivers early information in regard to the predisposition for the sport discipline dressage and jumping. High genetic correlations were determined between the corresponding traits of stallion performance test and the tournament competitions as well as competitions for young inexperienced horses, respectively (Schade, 1996; Brockmann, 1998). There were very high genetic correlations between the traits of stallion and mare performance test (Velsen-Zerweck and Bruns, 1998). These authors concluded based on the high genetic correlations between the stallion performance test and competition results (Schade, 1996) that traits of the mare performance test are also highly associated with competition performances.

Because of the numerous relationships among different traits of different performance tests and competitions a new integrated breeding value estimation is developed. The new integrated breeding value estimation is based on a multiple-trait repeatability animal model, considering simultaneously information from performance test of mares, performance test of stallion on station as well as all competition results (including non placed horses) of sport horses. Due to the simultaneous consideration of observation from mare and stallion performance test as well as the competition results of sport horses, a gain of information and accuracy will be achieved, and the bias of breeding values due to pre-selection are reduced.

At present, the used heritabilities for the new integrated breeding value estimation originate only from literature. Heritabilities and genetic correlations have to be estimated on the population of interest. Therefore, it is necessary to estimate the genetic parameters on the basis of the whole data used for the integrated breeding value estimation. The objective of this study was to estimated the genetic parameters of these traits used in the integrated breeding evaluation including all German warmblood breeds.

\section{MATERIALS AND METHODS}

Data of the integrated breeding value estimation and the following analyses are as follows:

- stallion performance tests from 1986 until 2001 (4527 stallions),

- mare performance tests from 1986 until 2001 (40,670 mares),

- results from competitions for young horses, which were build up for sport, from 1995 until 2001 (204,669 observations for dressage and 786,513 observations for show jumping),

- results from competitions of experienced horses from 1995 until 2001 (1,408,654 observations for dressage and 3,515,070 observations for show jumping). 
The 15 traits used in the integrated breeding evaluation are walk, trot, canter, rideability and free jumping from mare performance test and walk, trot, canter, rideability, free jumping and jumping under rider from stallion performance test. The four traits obtained from sport are dressage competition, show jumping competition for experienced horses as well as dressage and show jumping competition for young horses, which were build up for sport.

For mare and stallion performance test and competitions for young horses the recorded scores of the traits were used and for dressage and show jumping competition the transformed rank was used, which was the square root of place $\left(\mathrm{y}^{*}=11-\mathrm{y}^{0,5}\right)$. The statistic program package SAS (SAS Institut Inc., 2000) was used for the data preparation. For estimation of variance components, a multiple-trait animal model was fitted using multivariate REML program VCE 4.2.5 (Groeneveld, 1998).

The model for traits of stallion performance test and mare performance test is as follows:

$Y_{i j}=\mu+P_{i}+a_{j}+e_{i j}$

where $Y_{i j}$ is the observed score of each trait for the jth animal; $\mu$ is the population mean; $P_{i}$ is the fixed effect of the ith test group; $a_{j}$ is the random additive genetic effect of the jth horse; $e_{i j}$ is the random residual effect.

The model for traits of competition of experienced horses and competitions for young horses, which were build up for sport is:

$Y_{i j k l m}=\mu+P_{i}+A_{j}+R_{k}+p_{l}+a_{m}+e_{i j k l m}$ where $Y_{i j k l m}$ is the observed score of each trait for the mth animal; $\mu$ is the population mean; $P_{i}$ is the fixed effect of the ith competition; $A_{j}$ is the fixed effect of the jth combination of sex and age; $R_{k}$ is the fixed effect of the $k$ th combination of the performance group of rider and year or the rider directly, if the rider had in the same year enough starts with different horses (competition of experienced horses at least 50 starts with not less than five horses and competition for young horses at least 30 starts with not less than three horses); $p_{l}$ is the random effect of the lth permanent environment of the horse; $a_{m}$ is the random additive genetic effect of the mth horse; $e_{i j k l m}$ is the random residual effect.

\section{RESULTS}

Table 1 shows heritabilities and genetic correlations between the traits of stallion performance test. Heritabilities varied between 0.33 and 0.51. The dressage traits (walk, trot, canter and rideability) had high genetic correlations among each other. While walk and trot had low negative correlations to free jumping, showed canter a low positive correlation to free jumping. Canter and rideabilty were moderately correlated with jumping under rider. Whereas free jumping and jumping under rider were closely genetically related.

Heritabilities and genetic correlations for traits from mare performance test are presented in Table 2. Heritabilities ranged from 0.27 to 0.38 . Similar to the results for the stallion performance test, genetic correlations among the dressage traits were high. In contrast to stallion performance test, genetic relations of the gaits and rideability to free jumping were positive for mare performance test.

Heritabilities $\left(h^{2}\right.$, diagonal) and genetic correlations $\left(r_{g}\right)$ for traits of stallion performance test (SPT) (years 1986-2001; $n=4527$ )

\begin{tabular}{|c|c|c|c|c|c|c|}
\hline Trait & SPT walk & SPT trot & SPT canter & SPT rideability & $\begin{array}{c}\text { SPT } \\
\text { free jumping }\end{array}$ & $\begin{array}{c}\text { SPT jumping } \\
\text { under rider }\end{array}$ \\
\hline SPT walk & 0.34 & 0.75 & 0.74 & 0.67 & -0.15 & 0.03 \\
\hline SPT trot & & 0.51 & 0.85 & 0.84 & -0.06 & 0.03 \\
\hline SPT canter & & & 0.42 & 0.83 & 0.19 & 0.33 \\
\hline SPT rideability & & & & 0.41 & 0.04 & 0.21 \\
\hline SPT free jumping & & & & & 0.39 & 0.94 \\
\hline SPT jump. u. rider & & & & & & 0.33 \\
\hline
\end{tabular}

SE $\left(h^{2}\right): 0.02 ; \mathrm{SE}\left(\mathrm{r}_{\mathrm{g}}\right): 0.01-0.04$

Heritabilities $\left(h^{2}\right.$, diagonal) and genetic correlations $\left(r_{g}\right)$ for traits of mare performance test (MPT) (years 1986-2001; $n=39348$ )

\begin{tabular}{|c|c|c|c|c|c|}
\hline Trait & MPT walk & MPT trot & MPT canter & MPT rideability & $\begin{array}{c}\text { MPT } \\
\text { free jumping }\end{array}$ \\
\hline MPT walk & 0.27 & 0.66 & 0.64 & 0.69 & 0.12 \\
\hline MPT trot & & 0.38 & 0.82 & 0.81 & 0.21 \\
\hline MPT canter & & & 0.34 & 0.82 & 0.30 \\
\hline MPT rideability & & & & 0.29 & 0.20 \\
\hline MPT free jumping & & & & & 0.32 \\
\hline
\end{tabular}

SE $\left(h^{2}\right): 0.01 ;$ SE $\left(r_{g}\right): 0.01-0.02$ 
The genetic associations among traits from stallion and mare performance test are given in Table 3. The genetic correlations between the dressage traits recorded on stallion and mare performance test were on similar high level as in the specific performance tests. The gaits and rideability were low genetically related to free jumping at different performance test, for which canter resulted in the highest values. The genetic correlations between the dressage traits from mare performance test and jumping under rider from stallion performance test ranged from low to medium level. Free jumping from mare performance test were very high genetically related to jumping under rider from stallion performance test.

Genetic correlations $\left(r_{g}\right)$ between traits of stallion performance test (SPT) and mare performance test (MPT) (years 1986-2001; SPT: $n=4527$; MPT: $n=39348$ )

\begin{tabular}{|c|c|c|c|c|c|c|}
\hline Trait & SPT walk & SPT trot & SPT canter & SPT rideability & $\begin{array}{c}\text { SPT } \\
\text { free jumping }\end{array}$ & $\begin{array}{l}\text { SPT jumping } \\
\text { under rider }\end{array}$ \\
\hline MPT walk & - & 0.66 & 0.75 & 0.62 & -0.05 & 0.05 \\
\hline MPT trot & 0.65 & - & 0.79 & 0.74 & 0.05 & 0.13 \\
\hline MPT canter & 0.59 & 0.70 & - & 0.69 & 0.17 & 0.34 \\
\hline MPT rideability & 0.69 & 0.80 & 0.87 & - & 0.02 & 0.21 \\
\hline MPT free jumping & -0.09 & 0.04 & 0.14 & 0.07 & - & 0.86 \\
\hline
\end{tabular}

$\mathrm{SE}\left(\mathrm{r}_{\mathrm{g}}\right): 0.01-0.04$

In Table 4 are the genetic correlations among corresponding traits from stallion and mare performance test. The correlations were on a very high level and ranged from 0.87 to 0.98 (free jumping).

Table 4

Genetic correlations $\left(r_{g}\right)$ between corresponding traits of stallion performance test (SPT) and mare performance test (MPT) (years 1986-2001; SPT: $n=4527$; MPT: $n=39348$ )

\begin{tabular}{|l|r|r|}
\hline \multicolumn{1}{|c|}{ Trait } & \multicolumn{2}{c|}{$\begin{array}{c}\text { Genetic } \\
\text { correlation } \\
\text { SPT:MPT }\end{array}$} \\
\hline Walk & 0.88 & SE \\
\hline Trot & 0.90 & 0.03 \\
\hline Canter & 0.87 & 0.02 \\
\hline Rideability & 0.91 & 0.03 \\
\hline free jumping & 0.98 & 0.03 \\
\hline
\end{tabular}

SE $\left(r_{g}\right): 0.02-0.03$

Heritabilities and standard errors for competitions for young inexperienced horses are presented in Table 5. Heritabilities for dressage as well as for jumping competition of young horses were on low level and their standard error were low.

Table 5

Heritabilities $\left(h^{2}\right)$ and standard error (SE) for competitions for young inexperienced horses

\begin{tabular}{|l|r|r|r|}
\hline & $\begin{array}{c}\text { Observat } \\
\text { ions }\end{array}$ & \multicolumn{1}{|c|}{$\mathbf{h}^{2}$} & \multicolumn{1}{|c|}{ SE } \\
\hline $\begin{array}{l}\text { Dressage competition } \\
\text { for young horses }\end{array}$ & 92332 & 0.12 & 0.01 \\
\hline $\begin{array}{l}\text { Show jumping competition } \\
\text { for young horses }\end{array}$ & 74076 & 0.11 & 0.01 \\
\hline
\end{tabular}

\section{DISKUSSION AND CONLUSION}

Genetic correlations for traits from stallion performance test agrees with the results reported by the following author (Brockmann, 1998). Generally heritability for jumping traits were a little lower in the present study. The heritabilities and genetic correlations for the gaits and rideability from mare performance test correspond with the results from earlier publications (hertabilities: (Velsen-Zerweck and Bruns, 1998), genetic correlations: (Schade, 1996)). In the literature the differences between estimates for genetic correlation between the dressage traits and free jumping are remarkable. On the basis of data from the Hanoverian studbook negative genetic correlation between walk and free jumping were determined (Schade, 1996). In the latter study other dressage gaits showed low genetic relations to free jumping. Using data from the Holstein studbook, genetic correlations between the dressage traits and free jumping were of moderate magnitude ( $r_{\mathrm{g}}$ : 0.22-0.48) (Boesch et al., 2000). In the present study, the genetic correlations between the dressage traits and free jumping ranged from 0.12 to 0.30 . Obviously, there are differences between the German warmblood breeds. In the present study, about $40 \%$ of the mares in the data were tested by the Hanoverian studbook. Therefore, it will be necessary to examine whether a single German warmblood breed, influenced mainly the overall estimates and whether different parameters have to be used for different breeds.

In one of the latest studies about correlation between traits recorded on stallion and mare performance test, only the tested mares of the Hanoverian studbook were considered (Schade, 1996). In the present study, the clearly higher positive genetic correlation between walk and other gaits or rideability of different performance tests is remarkable. In the previous study determined negative correlations between the dressage traits from mare performance test and the trait jumping 
from stallion performance test cannot be verified in this study. Walk, trot and rideability from mare performance test seems not to be related to free jumping from stallion performance test. Canter from mare performance test was moderately positively correlated to the jumping traits from stallion performance test.

In a recent study, genetic correlations between corresponding traits of stallion and mare performance test were estimated on the basis of mare performance test data from six German warmblood studbooks and data of stallion performance test of the years 1986 until 1995 (Velsen-Zerweck and Bruns, 1998). The genetic correlations calculated in present study exceeded the genetic correlations of their study, which were already high. The very high genetic correlations indicates the similarity of the traits of stallion and mare performance test.

At the first analyses for competitions for young inexperienced horses with data about all started horses, for dressage and jumping competition of young horses heritability were estimated with $\mathrm{h}^{2}=0.35$ and $\mathrm{h}^{2}=0.14$, respectively (Brockmann, 1998). In the present study, heritability for dressage competition for young horses was substantially lower. The difference could be caused in the insufficient data structure of the previous study, because at that time only about ten percent of the whole data could be used (Brockmann and Bruns, 1998).
The present study verifies earlier studies about the importance of stallion and mare performance test for breeding. The heritabilities for the traits of stallion and mare performance test were on moderate magnitude, and therefore, allows successful work in breeding. It is shown that traits measured in stallion and mare performance test reflect the same traits even though they were measured in different environments and different sexes.

The use of all traits for estimation of genetic values of horses is expected to reduce pre-selection and optimal combines all information resources based on the estimated genetic parameters. Because of the simultaneous consideration of the available performance and competition results, there is a gain of information and accuracy. At present the total breeding value dressage from the integrated breeding value estimation is formed in equal parts from the individual breeding values of performance test information of mares and stallion and dressage competition of inexperienced young horses and dressage competition of experienced horses. The specific gaits and the rideability influence similarly the breeding value dressage of the stallion and mare performance test. Similar to the total breeding value dressage, the total breeding value jumping is determined out of the individual breeding values for jumping. The single breeding value of stallion performance test is formed from the free jumping and the jumping under rider.

\section{LITERATURE}

Boesch M.-Reinecke S.-Roehe R.-Kalm E. (2000): Genetische Analyse von Merkmalen in der Reitpferdezucht. Züchtungskunde, 72, 161-171.

Brockmann A. (1998): Entwicklung einer Eigenleistungsprüfung im Feld für Hengste unter Berücksichtigung der Turniersportprüfung. Dissertation Göttingen

Brockmann A.-Bruns E. (1998): Möglichkeiten der Prüfung von Hengsten im Feld. 2. Pferde-Workshop Uelzen - Aktuelle Fragen der Reitpferdezucht, Institut für Tierzucht und Tierhaltung der Universität Kiel, 58-64.

Groeneveld E. (1998): VCE4 User`s Guide and Reference Manual Version 4.2.5, Inst. Of Anim. Husbandry and Anim. Sci., Mariensee, Germany
Hassenstein C. (1998): Genetisch statistische Analyse von neuentwickelten Merkmalen aus Turniersportprüfungen für Reitpferde. Dissertation Kiel

Schade W. (1996): Entwicklung eines Besamungszuchtprogramms für die Hannoversche Warmblutzucht. Dissertation Göttingen

Velsen-Zerweck A.v.-Bruns E. (1998): Integrierte Zuchtwertschätzung unter Nutzung der Ergebnisse der Hengstleistungs- und Zuchtstutenprüfungen. 2. PferdeWorkshop Uelzen - Aktuelle Fragen der Reitpferdezucht, Institut für Tierzcht und Tierhaltung der Universität Kiel, 4148.

SAS Institut Inc. (2000): User`s Guide (release 8.1), Cary, NC. 